\title{
CURSO DE PEDAGOGIA DA UNIVERSIDADE FEDERAL DE SÃO PAULO: AVANÇOS E DESAFIOS
}

\author{
Lucila PESCE ${ }^{\mathrm{i}}$ \\ Edna MARTINS \\ Regina Cândida Ellero GUALTIERIiii
}

\begin{abstract}
RESUMO
O artigo apresenta o relato analítico dos desafios impostos ao curso de Pedagogia da Unifesp, desde sua criação. Inicia caracterizando o contexto de sua implantação, que teve dois fatores condicionantes: as DCNP (2006) e as Diretrizes do REUNI (2007). A análise do seu projeto pedagógico procura deslindar possíveis diferenciais e avanços, notadamente no que se refere aos princípios norteadores da sua matriz curricular, desde a primeira versão. A análise revela as tensões geradas pelas demandas sociais e pelos constrangimentos legais. O movimento analítico é desenvolvido com base na literatura específica da área e em teóricos do campo do currículo, como Goodson (1995) e Young (2014). O texto conclui apontando as ações até então empreendidas, no enfrentamento dos desafios que se lhe interpõem, à guisa de constante implantação de um currículo inovador, que se situe como um diferencial na formação do licenciando em Pedagogia.
\end{abstract}

PALAVRAS-CHAVE: Projeto pedagógico; Curso de Pedagogia; Currículo inovador.

\section{PEDAGOGY COURSE OF THE FEDERAL UNIVERSITY OF SAN PAULO: ADVANCES AND CHALLENGES}

\begin{abstract}
This paper presents a report of the challenges that are imposed to the course of Pedagogy of Unifesp. It begins with the characterization of the context of its implementation, which had two factors conditioning its proposal: The National Curriculum Guidelines for the Pedagogy Course, undergraduate (2006) and the Policy Guidelines REUNI (2007). The analysis of its pedagogical project seeks to unravel possible differentials and advances of the course, notably regard to the guiding principles of its curriculum matrix, since its first version. The analysis reveals the tensions generated from two sources: the social demands and the legal constraints. This analysis is developed based on the specific literature of the area and on theorists, in the field of the curriculum, such as Goodson (1995) and Young (2014). The text concludes pointing the actions developed to face the challenges, by a constant implementation of an innovative curriculum, which can be seen as a differential in the educational processes of the Pedagogy student.
\end{abstract}

KEYWORDS: Pedagogical project; Pedagogy course; Innovative curriculum.

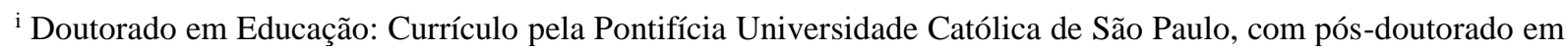
Filosofia e História da Educação, pela Universidade Estadual de Campinas. Professora Associada do Departamento de Educação da Universidade Federal de São Paulo. E-mail: lucilapesce@gmail.com.

ii Doutorado em Educação (Psicologia da Educação) pela Pontifícia Universidade Católica de São Paulo. Professora associada da Universidade Federal de São Paulo. E-mail: emartinsunifesp@gmail.com.

iii Doutorado em História Social pelo Departamento de História da USP. É docente no Departamento de Educação na Escola de Filosofia Letras e Ciências Humanas e nos Programas de Pós-Graduação em Educação e Educação e Saúde na Infância e na Adolescência da Universidade Federal de São Paulo. E-mail: recan@ uol.com.br.

$======$

Revista e-Curriculum, São Paulo, v. 18, n.3, p.1140-1159 jul./set. 2020

Programa de Pós-graduação em Educação: Currículo - PUC/SP

e-ISSN: $1809-3876$

http://revistas.pucsp.br/index.php/curriculum 


\section{CURSO DE PEDAGOGÍA DE LA UNIVERSIDAD FEDERAL DE SAN PABLO: AVANCES Y DESAFÍOS}

\section{RESUMEN}

El articulo presenta un informe analítico sobre los desafíos que se le imponen al curso de Pedagogía de la Unifesp. El texto comienza con la caracterización del contexto de su implementación, que tenía dos factores que condicionan su propuesta: las Directrices Curriculares Nacionales para el Curso de Pedagogía (2006) y las Directrices Políticas del Programa REUNI (2007). El análisis del proyecto pedagógico del curso busca desentrañar sus posibles diferenciales y avances, especialmente con respecto a los principios rectores de su matriz curricular, desde su primera versión. El análisis revela las tensiones generadas, a partir de dos fuentes: las demandas sociales y las restricciones legales. El análisis se desarrolla con base en la literatura específica del área y en teóricos, en el campo del currículum, como Goodson (1995) y Young (2014). El texto concluye señalando las acciones realizadas hasta el momento, para enfrentar los desafios que se interponen, a través de la implantación constante de un currículum innovador, que puede verse como un diferencial en los procesos educativos de los estudiantes de Pedagogía.

PALABRAS CLAVE: Proyecto pedagógico; Curso de Pedagogía; Currículum innovador.

\section{HISTÓRICO E CONTEXTO DE IMPLANTAÇÃO DO CURSO}

O Curso de Pedagogia da Universidade Federal de São Paulo - Unifesp começou a se estruturar no final de 2005, em meio aos debates que envolveram a elaboração e a aprovação das Diretrizes Curriculares Nacionais para o Curso de Pedagogia, licenciatura (DCNP), instituídas em maio de 2006, pelo Conselho Nacional de Educação (Resolução CNE/CP nº 1 , de 15 de maio de 2006). Essa formulação legal impôs tanto a reformulação dos cursos existentes quanto os moldes de organização dos que viessem a ser criados. Em essência, as DCNP estabeleceram a centralidade do curso de Pedagogia na formação docente, a partir da compreensão da docência como uma função que se estende para além do magistério e inclui a gestão de sistemas e instituições, bem como a produção de conhecimento.

Esse conceito expandido de docência, ou esse "alargamento" da concepção de docência que "vai para além das atividades de ensino-aprendizagem", como bem avaliam Evangelista e Trinches (2017), foi incorporado às DCNP para acomodar as várias visões em disputa à época de sua formulação, sem a correspondente verticalização teórica (EVANGELISTA e TRINCHES, 2017, p. 179 e 184).

Soma-se a isso o fato de o marco legal não ter sido consensual entre os educadores, que se dividiram entre os que defendiam e os que não apoiavam a docência como base para a 
formação dos pedagogos. Desta celeuma resultaram a indistinção entre licenciatura e bacharelado e a extinção das habilitações, tendências essas que preponderaram nas diretrizes curriculares de diversos cursos de graduação e foram incorporadas às DCNP (2006). Por isso, as Diretrizes de Pedagogia de 2006 representaram, para alguns, "uma solução negociada entre entidades e o Conselho Nacional de Educação" (SCHEIBE, 2007, p. 43) ou um "consenso alcançado no tensionamento das duas propostas" (DURLI, 2007 apud BRANDT, HOBOLD, 2019, p. 7) e, para outros, "uma solução, mesmo que provisória, para uma controvérsia que vem se arrastando nos últimos 25 anos, sem perspectiva de negociação e muito menos de consenso" (RODRIGUES, KUENZER, 2007, p. 35).

A licenciatura em Pedagogia, proposta pelas Diretrizes (2006), deveria formar profissionais para exercer a docência na Educação Infantil, nos anos iniciais do Ensino Fundamental, nos cursos de Ensino Médio, na modalidade Normal de Educação Profissional na área de serviços e apoio escolar e em outras áreas em que sejam previstos conhecimentos pedagógicos, no contexto formal e não-formal.

Considerando que o curso de Pedagogia tem longa tradição na vida acadêmica brasileira e é um dos mais ofertados pelas instituições de ensino superior, organizar uma proposta curricular com a amplitude de responsabilidades formativas preconizada pelas DCNP é, por si só, um enorme desafio. Contudo, havia ainda outros desafios, associados a esse, colocados no texto legal e, sobretudo, explicitados nos debates da época, que apontavam para a importância de que um curso de formação inicial docente, em geral e, em particular o de Pedagogia, superasse a dicotomia entre teoria e prática, a separação entre ensino e pesquisa e a distância entre formação acadêmica e formação prático-profissional.

Foi, portanto, nessa atmosfera que o projeto pedagógico do Curso de Pedagogia da Unifesp começou a ser concebido.

Outro elemento determinante na elaboração e na implementação desse projeto pedagógico está relacionado ao fato de que o Curso foi criado com a expansão do sistema público federal de educação superior, decorrente do Programa de Apoio a Planos de Reestruturação e Expansão das Universidades Federais - REUNI (instituído pelo Decreto ${ }^{\circ}$ 6.096, de 24 de abril de 2007). Esse Programa pressupunha, entre outras ações, reestruturações acadêmicas e curriculares, com propostas inovadoras que propiciassem "maior mobilidade estudantil, trajetórias de formação flexíveis, redução das taxas de evasão, utilização adequada 
dos recursos humanos e materiais colocados à disposição das universidades federais". (BRASIL, 2007, p. 9). A existência de flexibilidade curricular nos cursos de graduação estava, assim, entre os objetivos do Programa e visava a permitir "a construção de itinerários formativos diversificados e que facilitasse a mobilidade estudantil". (BRASIL, 2007, p.10). Desse modo, o Programa estimulava os participantes a construir propostas pedagógicas inovadoras. Em suma, o projeto pedagógico do Curso de Pedagogia da Unifesp se delineou com base nesses dois parâmetros: as DCNP (2006) e o Programa REUNI (2007).

A primeira versão do projeto pedagógico foi escrita entre 2005 e 2006, por uma equipe de consultores. Com a contratação do primeiro quadro que integrou o corpo docente, o Projeto Pedagógico do Curso (PPC) foi revisto, considerando o projeto multidisciplinar da Escola de Filosofia, Letras e Ciências Humanas da Unifesp - EFLCH (campus Guarulhos), como será apontado mais adiante neste texto. Na ocasião estabeleceu-se, ainda, um conjunto de metas para a formação de professores e gestores educacionais, em estreita articulação com as redes públicas de educação básica do município de Guarulhos, mediante convênio de cooperação técnica com a Secretaria Municipal de Educação de Guarulhos e com as Diretorias Regionais da Secretaria de Educação do Estado de São Paulo, que se localizam no entorno do campus Guarulhos.

Como já afirmado, as DCNP constituem um desafio para todo elaborador que pretenda garantir um currículo que atenda à formação múltipla pretendida - docente em diferentes níveis e modalidades, gestor de instituições de ensino e de sistemas e pesquisador. No caso do PPC de Pedagogia da Unifesp, essa multiplicidade se acomodou em uma matriz curricular estruturada em três eixos: a) o das unidades curriculares ou disciplinas básicas voltadas aos conhecimentos teóricos e práticos relativos ao trabalho pedagógico da docência e da gestão; b) o das disciplinas consideradas prático-profissionalizantes, que abrangem a atuação na Educação Infantil, nos anos iniciais do Ensino Fundamental, na Gestão da Educação Básica bem como em práticas educativas em cenários de aprendizagem não-escolar; c) o das disciplinas eletivas destinadas a complementar a formação do graduando, de acordo com seus interesses, além de estudos de enriquecimento curricular. (São Paulo, 2019). Nessa direção, pela especificidade e finalidade dos eixos, a maior parte das disciplinas tem caráter obrigatório.

O fato é que a multiplicidade de formações e atuações previstas para os cursos de licenciatura em Pedagogia de certa forma colidiu com a proposta do REUNI de inovar, prevendo itinerários formativos diversificados. Garantir aquela formação múltipla exige o trânsito do aluno por um conjunto mínimo de unidades curriculares. Isso, além de congestionar 
o currículo, fragmenta as discussões e dificulta o aprofundamento das temáticas. Essas fragilidades decorrem dos pressupostos das DCNP e dificilmente haverá solução, no âmbito exclusivo de um determinado curso. Todavia, mesmo assim, no caso da Pedagogia da Unifesp, tem ocorrido constantes avaliações e discussões, por parte do corpo docente e dos estudantes. Consequentemente, têm ocorrido vários ajustes na matriz curricular, sobretudo no conjunto das disciplinas básicas, com supressão de algumas e inserção de outras, para atender aos interesses dos licenciandos e às necessidades formativas que surgem na dinâmica educacional.

Nos anos de 2011 e 2012 houve alterações no PPC e, em 2014, realizou-se uma avaliação abrangente do Curso, em consulta (mediante questionário e audiência) a todos os estudantes e ao conjunto dos professores. Os dados foram sistematizados e analisados pelo Núcleo Docente Estruturante (NDE). Com base em tal análise e tendo como referência documentos legais - Diretrizes Curriculares para o Curso de Pedagogia (CNE/CP n. ${ }^{\circ}$ 5/2005 e CNE/CP n. ${ }^{\circ}$ 1/2006) e Portaria Inep n. ${ }^{\circ}$ 263/2014 (ENADE - Área de Pedagogia) - e institucionais, como o Relatório Final de Integralização (Prograd, 2014), o NDE propôs alterações que tramitaram internamente ao curso e institucionalmente. Assim sendo, uma nova matriz entrou em vigor em 2015. Porém, as mudanças prosseguiram. No ano de 2019, outros ajustes foram propostos e uma nova matriz entrou passou a vigorar em 2020.

Contudo, a rediscussão das DCNP relativa ao destino profissional de seus egressos é, sem dúvida, um ponto crucial para enfrentar os problemas da formação inicial dos pedagogos, em conexão com os problemas da Educação Infantil, em plena expansão no Brasil e da educação dos anos iniciais do Ensino Fundamental, em função da melhoria requerida nos processos de alfabetização e letramento científico e humanístico. Há que se pensar em um reequilíbrio nessa formação, que não se restrinja a hipertrofiar a formação em disciplinas de caráter práticoprofissionalizante, o que, inevitavelmente, resulta em reducionismos indesejáveis. Há que se pensar até mesmo em possíveis separações das várias formações, hoje concentradas em um curso polivalente.

Tais reducionismos, aliás, já têm sido apontados em pesquisas recentes, como, por exemplo, a de Micheletti e Galian (2017) as quais analisam, em um estudo qualitativo, mudanças na formação inicial induzidas pelas DCNP, em uma universidade na cidade de São Paulo. Elas concluem que, nessa formação, há 
[...] uma perda bastante significativa das disciplinas de Fundamentos da Educação, por meio de um corte de aproximadamente metade da carga horária, acompanhado de uma ampliação das disciplinas de Formação Docente núcleo no qual já se tinham implantado 18 disciplinas em 2003 e que acaba incorporando mais 16 disciplinas após as DCNP, passando de $32 \%$ para 55,2\% da carga horária total do curso (MICHELETTI, GALIAN, 2017, p. 1699).

De modo semelhante, a pesquisa de Pimenta et al. (2017) revela que a maioria dos cursos, no estado de São Paulo, é oferecida com cargas horárias mínimas e a maior parte dessa carga horária refere-se a conhecimentos relativos à formação profissional docente (em torno de $38 \%$ da carga horária dos cursos). Os conhecimentos relativos aos fundamentos teóricos foram contabilizados em torno de $16 \%$. Para os autores, ainda que tal percentual possa parecer um percentual expressivo, ele se caracteriza como insuficiente para garantir uma formação básica na área da educação, área que exige "multirreferencialidade em diferentes campos científicos como sociologia e filosofia da educação, por exemplo" (PIMENTA et al., 2017, p. 22). Ao mesmo tempo, essa pesquisa aponta outro dado importante: a existência, nos cursos pesquisados, de um quadro curricular com grande diversidade de disciplinas "muitas delas sem aderência à docência e às questões próprias dos anos iniciais da educação básica" (PIMENTA et.al., 2017, p. 22).

No que diz respeito aos outros desafios apresentados para a formação inicial, mencionados anteriormente, quais sejam, o de superar a dicotomia entre teoria e prática e a separação entre ensino e pesquisa, o corpo docente do Curso tem buscado enfrentá-los. Nesse sentido, a incorporação na matriz curricular de disciplinas como "Práticas Pedagógicas e Pesquisa" e "Residência Pedagógica" (estágios obrigatórios) - considerados dois dos diferenciais do curso - representa uma tentativa desse enfrentamento e será analisada no próximo item do presente texto.

A análise, ora apresentada, dos diferenciais do curso de Pedagogia da Unifesp não perde de vista o que Goodson (1995) sugere, quando enfatiza a importância da abordagem combinada que enfoque a construção de currículos prescritivos e a realização desses currículos.

Precisamos entender a construção social de currículos nos níveis de prescrição e do processo prático. O que se requer é, na realidade, um entendimento do aspecto prático, evitando situar este entendimento dentro de uma ulterior exploração dos parâmetros contextuais da prática (GOODSON, 1995, p. 72). 
Assim, com a intenção de entender o processo prático que derivou do currículo prescrito, são traçados e problematizados determinados aspectos da história recente de ações curriculares desenvolvidas no Curso de Pedagogia em tela. Ações que vêm acontecendo em um contexto de tensões e conflitos resultantes das DCNP, como mostrado, mas também de exigências sociais decorrentes da ampliação dos debates sobre diversos direitos - das crianças de 0 a 6 anos, da pessoa com deficiência, dos jovens e adultos não escolarizados na idade prevista, das relações étnico-raciais, entre outros - trazem repercussões no Ensino Superior que implicam redefinições na natureza de seus cursos, em seus conteúdos e em suas pesquisas. Nessa circunstância, o Curso de Pedagogia tem sido demandado a preparar um profissional capaz de implementar as políticas educacionais advindas dessas exigências sociais e tem tido de responder às demandas, como será discutido no item 2 deste texto.

As discussões das ações curriculares para responder a essas demandas são acompanhadas da perspectiva analítica de Young (2014), para quem a questão crucial a ser respondida é:

qual conhecimento deveria compor o currículo? Não no sentido absoluto de conhecimento verdadeiro, o que seria mais bem definido como crença, mas no sentido de 'o melhor conhecimento que temos em qualquer campo' (YOUNG, 2014, p. 197).

Esse autor identifica o "melhor conhecimento" como "conhecimento poderoso", ou seja, o conhecimento "capaz de prover os alunos de recursos para explicações e para pensar alternativas, qualquer que seja a área de conhecimento e a etapa da escolarização". O "conhecimento poderoso" se distingue do "conhecimento dos poderosos", um "sistema de relações sociais e de poder com uma história específica" que o currículo também é (YOUNG, 2014, p. 201).

Sobre essa distinção, Young faz um alerta importante, ao argumentar que as análises de currículos nem sempre estabeleceram um bom equilíbrio entre esses dois aspectos e privilegiaram o currículo como "conhecimento dos poderosos".

[...] a teoria do currículo não estabeleceu um bom equilíbrio entre esses dois aspectos. Concentrou-se demasiadamente no currículo como "conhecimento dos poderosos" - um sistema concebido para manter as desigualdades educacionais - e negligenciou o currículo como "conhecimento poderoso" (YOUNG, 2014, p. 201). 
As discussões e análises efetivadas no item 3, mas também no 2, procuram levar em conta esse importante alerta de Young (2014).

\section{DIFERENCIAIS DO CURSO DE PEDAGOGIA DA UNIFESP}

O curso de Pedagogia da Unifesp possui algumas características que foram pensadas para atender ao caráter multidisciplinar de formação para os alunos da Escola de Filosofia, Letras e Ciências Humanas da Unifesp (EFLCH). Um dos diferenciais da matriz curricular é a presença de disciplinas denominadas "Domínios Conexos" (DC). Tais unidades curriculares (UC) representam as disciplinas que qualquer aluno pode cursar fora de seu curso de origem. Desse modo, os estudantes de Pedagogia podem realizar disciplinas de Domínio Conexo que são ofertadas semestralmente por outros cursos da EFLCH, quais sejam: Ciências Sociais, Filosofia, Letras, História e História da Arte. Também são oferecidas essas unidades de DC pelo curso de Pedagogia, de modo a permitir que os estudantes de outros cursos possam cursálas, juntamente com os estudantes de Pedagogia. Nesse sentido, tais UC possibilitam flexibilidade e diversidade de olhares para o estudante, além de permitir que todos transitem em diversos campos de conhecimento, ampliando a interação e as trocas entre os grupos de estudantes de todo o campus da EFLCH.

A posição dos docentes do curso de Pedagogia da Unifesp é a de que as UC de Domínio Conexo são fundamentais para a formação dos estudantes, pois atendem às orientações assinaladas nas Diretrizes Curriculares Nacionais para o Curso de Graduação em Pedagogia e nas Diretrizes Nacionais para a Formação de Professores da Educação Básica, as quais estabelecem a importância da formação para a docência construída na relação com outros campos do saber, como Filosofia, Psicologia, História, Sociologia, Ciências Naturais, Linguagens, Arte, dentre outros.

No projeto pedagógico inicial do campus Guarulhos estava previsto que os estudantes de todos os cursos deveriam frequentar duas unidades curriculares (UC) de Domínio Conexo obrigatórias e fixas. Tais UC estavam previstas nas matrizes curriculares dos distintos cursos do campus, para garantir que todos tivessem uma formação comum. Tais UC eram ministradas pelos professores do curso de Filosofia e organizadas de tal modo que estudantes de todos os cursos do campus pudessem ter acesso e opção de matrícula. A cada semestre eram oferecidas 
7 (sete) turmas de cada uma das UC, para que todos pudessem ter sua vaga garantida. O propósito dessa oferta era poder propiciar aos estudantes uma compreensão global dos fundamentos filosóficos das Ciências Humanas, possibilitando o acesso a textos originais e críticos, com bibliografia tradicional de teorias das áreas de Filosofia e Ciências Humanas. Buscava-se, portanto, favorecer o desenvolvimento de habilidades de leitura, interpretação e reflexão sobre textos desse campo do saber. Nesse núcleo obrigatório comum, duas Unidades Curriculares foram ofertadas até o primeiro semestre do ano de 2019: "Filosofia Geral" e "Leitura e Interpretação de Textos Clássicos”.

No decurso de dez anos de existência da EFLCH, em que os alunos vivenciaram tais Unidades Curriculares, elas foram sendo avaliadas por discentes e professores de todos os cursos do campus. Cada curso, considerando suas especificidades, realizou discussões com seu alunado e em seus colegiados sobre a oferta dessas duas Unidades Curriculares obrigatórias. A partir de então decidiu-se, por unanimidade, a proposição de que tais disciplinas passassem a ser ofertadas com o status de eletivas, como já ocorre em outras UC ofertadas pelos cursos do campus Guarulhos. Desse modo, a partir de 2020 as ofertas de todas as UC de Domínio Conexo do campus passam a ser feitas, de modo que os estudantes possam escolher livremente quais desejam cursar. O intuito é possibilitar a existência de percursos formativos nos quais os estudantes do campus tenham mais opções para conduzir a sua formação geral. Nesse movimento, o curso ainda garante que as disciplinas de Domínio Conexo possam continuar oferecendo espaço de interação aos alunos de todas as licenciaturas do campus, a partir da multiplicidade de visões das Ciências Humanas e Sociais, contemplando temáticas e objetos de estudo variados que oportunizem aprendizagens, em respeito à diversidade e à pluralidade de interesses dos envolvidos.

Outro diferencial do curso de Pedagogia da Unifesp diz respeito ao campo do estágio supervisionado obrigatório, que funciona desde 2009 por meio do Programa de Residência Pedagógica (PRP). Esse Programa integra as disciplinas do Curso e está organizado de modo a contemplar quatro áreas de formação docente, quais sejam: a) Educação Infantil, b) Ensino Fundamental I (anos iniciais), c) Educação de Jovens e Adultos, d) Gestão Educacional. Tais modalidades são representadas por 4 (quatro) disciplinas práticas que substituem os tradicionais estágios curriculares previstos na formação de professores, sendo obrigatórias para todos os estudantes matriculados no Curso. 
É oportuno observar que todos os docentes do Curso participam do Programa de Residência Pedagógica, assumindo a preceptoria de pequenos grupos de estudantes. Esse formato permite que os docentes acompanhem muito proximamente os residentes, no decurso de sua imersão nas escolas das redes de educação conveniadas, denominadas pelo Programa como escolas-campo.

A partir de 2018, a carga horária prevista para os estágios obrigatórios, determinada pela Resolução de $n .^{\circ} 2$, de $1^{\circ}$ de julho de 2015, foi acrescida de mais 100 horas, passando de 300 para 400 horas. Desse modo, a organização das unidades curriculares de Residência Pedagógica passou a obedecer a seguinte carga horária: Residência Pedagógica Educação Infantil (135 horas); RP Ensino Fundamental I (135 horas); RP Educação de Jovens e Adultos (65 horas) e RP Gestão Educacional (65 horas).

Como já dito, o Programa de Residência Pedagógica funciona a partir de acordos de cooperação técnica da Unifesp com escolas da rede pública de Guarulhos e com algumas Diretorias de Educação da Secretaria de Educação do Estado de São Paulo (na modalidade Gestão Educacional), que estão nas cercanias da Universidade. A adesão das escolas parceiras ocorre de forma voluntária e, a partir do acordo de cooperação técnica, os educadores que recebem os estudantes em suas salas de aulas comprometem-se a contribuir para a formação dos estagiários (residentes) durante o período de imersão na escola. Tal experiência vem sendo tratada por pesquisadores como uma proposta pioneira no campo de formação de professores:

A primeira experiência de residência na formação inicial de professores encontrada (cronologicamente anterior às demais) foi o Programa de Residência Pedagógica (PRP), implementado desde 2009, no curso de Pedagogia da Universidade Federal de São Paulo (UNIFESP). De acordo com trabalhos que relatam essa experiência, o PRP é um modelo de estágio supervisionado obrigatório que articula a formação inicial à formação continuada de professores que atuam nas escolas públicas da cidade de Guarulhos que estabeleceram Acordos de Cooperação Técnica com a UNIFESP (FARIA e DINIZ-PEREIRA, 2019, p. 339-340).

Estudos sobre o Programa de Residência Pedagógica da Unifesp têm demonstrado que essa tem sido uma experiência inovadora e exitosa, em que a relação teoria e prática tem sido respeitada e levada a cabo, a partir do contato dos estudantes em processo de formação para a docência, com a realidade da escola pública brasileira (MARTINS, 2012; GIGLIO e LUGLI, 2013; MORETTI e MARTINS, 2015; MARTINS, CARVALHO e CÂNDIDO, 2019). 
Tais pesquisas têm apontado que a experiência de estágio curricular, a partir desse Programa, tem contribuído para a formação dos estudantes, na medida em que oportuniza vivências de imersão a campo (e não idas pontuais à escola), em situações cotidianas pautadas no contexto da escola pública. Nesse contexto, a discussão dos temas emergentes nas escolas com os professores orientadores da Universidade tem servido como preciosa fonte de aprendizado, na medida em que eventos, ações e práticas educativas podem ser tomadas como objeto de estudo e reflexão, pelos residentes, à busca de uma escola pública de qualidade social (CONAE, 2018).

Tais aspectos observados e discutidos pelos envolvidos são constantemente levados para as discussões com os professores formadores e gestores das escolas que recebem os residentes. Essa dinâmica tem resultado em processos de formação continuada daqueles que já se encontram envolvidos com o trabalho educativo nas escolas-campo, como sintetizado por Giglio e Lugli (2013, p. 66):

\begin{abstract}
Essa experiência que envolve tempos e espaços determinados destoa em muitos aspectos da maior parte dos estágios de formação de professores e gestores: a) os residentes têm compromisso com as escolas-campo e sua permanência ocorre de forma sistemática e por tempo diário mínimo determinado (4 horas de permanência mínima); b) o tempo de residência é todo dedicado a atividades na escola e à supervisão com os preceptores que oferecem assessoria para a elaboração de projetos de ação pedagógica na docência e orientações na gestão escolar; c) os estágios tradicionais, de modo geral, deixam ao estudante o arbítrio sobre a frequência (dias da semana em que frequentará o estágio e quantidade de horas diárias), ou estabelece o dia do estágio na grade semanal de aulas; isso não ocorre na residência; d) muitos estágios são realizados mantendo os estagiários numa quantidade mínima de horas em contato com os cenários profissionais de aprendizagem, contabilizando como estágios as horas de estudo, a pesquisa sobre o entorno das escolas, a análise documental/legal e os tempos destinados à elaboração de relatórios de estágio dentre outros; isso não é contabilizado nas horas de Residência.
\end{abstract}

Embora o Programa de Residência Pedagógica tenha, durante esses últimos dez anos, se mostrado como experiência promissora na formação de professores, ainda há muitos desafios a enfrentar. Dentre as dificuldades destacam-se duas: a) a falta de disponibilidade de tempo de alguns estudantes trabalhadores para cumprir as horas do Programa, que requer muito tempo de imersão em escolas específicas do entorno da Universidade; b) a resistência de alguns professores das escolas-campo às propostas da Universidade, ainda que essas sejam discutidas 
em processos de parceria, considerando a "estrutura e a dinâmica de pessoal nas escolas", como constatado por Giglio e Lugli (2012, p. 80).

Para vencer esses e outros desafios, os docentes do curso de Pedagogia da Unifesp, em sua atuação como preceptores no Programa de Residência Pedagógica, têm buscado estreitar laços com os professores das escolas que recebem os estudantes em sala de aula. A premissa é a de que a imersão na escola e a preceptoria, no âmbito da Universidade, constituem-se como uma díade formativa de valor ímpar. Desse modo:

No processo de imersão espera-se que o residente não apenas observe, mas possa dar apoio ao professor de classe em suas práticas pedagógicas [...] Cotidianamente tais residentes devem ser encorajados a atuarem com pequenas ações junto às crianças com a orientação dos professores que o acompanham. [...] No processo intenso de imersão na realidade da escola, os residentes devem construir registros diários das experiências vividas em campo, além de outros materiais que têm origem na observação participativa do dia a dia escolar e servirão de avaliação final, tendo elaboração orientada e aferida pelo professor preceptor da Universidade (MARTINS, CARVALHO e CANDIDO, 2019, p. 7).

Quando estão em imersão, os residentes também devem construir pequenos planos de ação pedagógica, que são aplicados junto às turmas em que estão inseridos. Estes planos são construídos em acordo com os professores formadores da escola-campo. Antes da aplicação dessas ações, os residentes apresentam seus planos aos professores formadores e à coordenação da escola, na reunião realizada na "Hora Atividade" (H.A.). Nessas ocasiões, há uma intensa troca de saberes teóricos e práticos entre universidade e escola, que tem contribuído para aproximar e fomentar parcerias entre ambas as instituições. É nesse momento que "os estudantes compartilham seus conhecimentos, suas experiências, expectativas, apreensões e onde explicitam-se possibilidades de articulação escola-universidade no âmbito da formação de professores" (MARTINS, CARVALHO e CANDIDO, 2019, p. 7).

A parceria entre escola e universidade também tem se fortalecido, na medida em que esse processo tem envolvido o trabalho dos professores do curso de Pedagogia da Unifesp, em ações de formação continuada ofertadas nas escolas participantes do convênio de cooperação técnica entre a Unifesp, a Secretaria Municipal de Educação de Guarulhos e as Diretorias Regionais de Educação da Secretaria de Educação do Estado de São Paulo que estão no entorno da Universidade. Dito de outro modo, os professores do curso de Pedagogia da Unifesp, sempre que solicitados, vão às escolas-campo, para participar de ações de formação continuada em 
serviço in loco, no trabalho coletivo desenvolvido em HA, em atendimento a temas emergentes no cotidiano escolar. Constantemente, professores e coordenação das escolas-campo são convidados a participar de eventos acadêmicos na Universidade, inclusive como palestrantes, dando sua oportuna contribuição à formação dos graduandos em Pedagogia, mediante depoimento reflexivo de inúmeras questões afeitas ao dia a dia da escola. Alguns apresentam seus trabalhos em conferências para toda a comunidade universitária. Outros acabam ingressando nos programas de pós-graduação da Unifesp, onde realizam suas pesquisas de mestrado e doutorado.

Além do Programa de Residência Pedagógica, outro diferencial da matriz curricular do curso de Pedagogia da Unifesp é a disciplina Práticas Pedagógicas e Pesquisa (PPP). De acordo com Giglio e Lugli (2012), as PPP foram organizadas com o intuito de oportunizar o acesso dos licenciandos aos diferentes modos, métodos, técnicas e práticas de pesquisa dentro e fora de ambientes escolarizados. Tal iniciativa envolve o trabalho com o desenvolvimento de pesquisa de campo de inspiração etnográfica, pesquisa documental, assim como o conhecimento e o aprimoramento de técnicas de observação e intervenção, na compreensão do fenômeno educacional. $\mathrm{O}$ oferecimento das PPP não segue um formato rígido e tem como característica principal uma diversidade de linhas de pesquisa e propostas de ação oferecidas semestralmente por muitos docentes do departamento de Educação, cabendo ao estudante escolher em qual proposta se inserir. A oferta das diferentes linhas de pesquisa pode ser mantida ou modificada, a cada semestre. O trabalho de cada linha de pesquisa envolve um professor orientador, que acompanha um pequeno número de estudantes (até 10), com uma proposta de ação que pode ser realizada dentro ou fora do campus universitário, em situação distinta da prática pedagógica ocorrida em sala de aula. Ao final de cada semestre, cada linha de pesquisa apresenta o seu produto, em formato de exposição de pôsteres que são apresentados e discutidos por todos os grupos participantes: alunos, professores e convidados. Para se ter uma ideia do trabalho das PPP, elencam-se as seguintes linhas de pesquisa trabalhadas em dois semestres consecutivos:

Linhas de trabalho desenvolvidas em PPP e oferecidas no primeiro semestre, aos turnos vespertino e/ou noturno:

- $\quad$ Linha 1 - Conhecendo os sistemas de ensino paulista: estado e municípios.

- Linha 2 - Crianças com redução de mobilidade: apetrechos, instituições e técnicas do corpo. 
- $\quad$ Linha 3 - Ensino e aprendizagem em espaços não formais e informais.

- $\quad$ Linha 4 - Clube de Matemática: jogos africanos.

- $\quad$ Linha 5 - Humanidades digitais: construção de base de dados para a pesquisa em história do ensino de matemática nos anos iniciais escolares.

- Linha 6 - Experiências com a escrita criativa.

Linhas de trabalho desenvolvidas em PPP e ofertadas no segundo semestre, aos turnos vespertino e/ou noturno:

- $\quad$ Linha 1 - Uma proposta de compreensão das práticas pedagógicas por meio dos cadernos escolares.

- $\quad$ Linha 2 - Literatura infantil e diferenças: representações da deficiência para a infância.

- $\quad$ Linha 3 - Iniciação à prática de contação de histórias.

- Linha 4 - A constituição de acervos literários e a formação de leitores: quais critérios de escolha?

- $\quad$ Linha 5 - Leituras de clássicos da educação e experiências educacionais inovadoras.

- Linha 6 - Culturas afro-brasileira e indígena: entre práticas sociais e políticas públicas.

Como ocorre em outras instituições de ensino superior, além de cursar disciplinas obrigatórias e um grupo de disciplinas eletivas, os estudantes do curso de Pedagogia da Unifesp podem se vincular a diversos projetos de desenvolvimento docente, como o projeto de monitoria e o PIBID - Programa Institucional de Iniciação à Docência, em projetos de pesquisa como o PIBIC - Programa Institucional de Bolsa de Iniciação Científica, com acompanhamento dos docentes do departamento de Educação.

Há também a presença de muitos grupos de estudos organizados por professores do Curso, nos quais participam os alunos de Pedagogia, juntamente com pesquisadores externos convidados e com estudantes de dois Programas de Pós-graduação do Departamento (PPGE Educação; PPGES - Educação e Saúde). 
Os estudantes são também encorajados a participar de vários programas, projetos e outras ações de extensão, que ocorrem no âmbito do campus ou externamente, como, por exemplo, o projeto Unifesp e Belas Artes, desenvolvido na brinquedoteca, sob orientação da professora Célia Serrão.

Por fim, outro diferencial do Curso é a oferta de vagas para professores da rede pública (municipal de Guarulhos, estadual de São Paulo), em diversas disciplinas da graduação. Essa abertura é muito fecunda, por possibilitar maior interação entre universidade e escola e por permitir aos licenciandos em Pedagogia discutir sobre aspectos educacionais, em diálogo profícuo com os professores que já atuam na educação básica.

\section{DESAFIOS ENFRENTADOS E A ENFRENTAR}

No que diz respeito aos desafios externos ao curso, há diversos fatores que impactam negativamente a permanência dos estudantes no Curso, dentre os quais destaca-se a dificuldade de acesso, posto que o campus se localiza em uma região periférica de Guarulhos que apresenta dificuldades de locomoção, em termos de transporte público (São Paulo, 2016). Destaca-se, também, a preocupação com a possibilidade de descontinuidade de políticas afirmativas, materializadas, por exemplo, na verba destinada ao restaurante universitário, ao NAE - Núcleo de Apoio ao Estudante, ao NAI - Núcleo de Apoio à Inclusão. Tais políticas afirmativas, de certo modo condicionam circunstâncias mais favoráveis à permanência estudantil, sobretudo levando-se em consideração o perfil socioeconômico desprivilegiado da extensa maioria dos estudantes do campus da EFLCH (SÃO PAULO, 2016).

No tocante aos desafios internos ao Curso cumpre observar que, durante a gestão julho de 2017-julho de 2019, a equipe gestora procedeu à elaboração de uma nova análise da matriz curricular, considerando alguns desafios até então não vencidos. Um deles dizia respeito à necessidade de se tematizar o campo da educação inclusiva, das teorias pedagógicas e das relações étnico-raciais, em disciplinas obrigatórias, de modo a garantir que todos os estudantes do curso tenham acesso aos estudos dos supracitados campos conceituais. Isso porque, até então, tais áreas do conhecimento eram tematizadas por unidades curriculares ofertadas em caráter eletivo. 
Outro desafio referia-se à necessidade de se incluir as atividades das PPP (Práticas Pedagógicas e Pesquisa) na matriz curricular, de modo a garantir um dia da semana exclusivo para esse percurso formativo. Isso porque, de 2007 a 2019, a matriz curricular previa a oferta de quatro PPP aos termos 1 a 4. Os encontros mensais na Universidade eram inseridos em dias da semana alternados, ocupando (naquele encontro mensal) o espaço de outra disciplina. Nas demais semanas do mês, as PPP previam estudos de campo. A partir de 2020, a matriz curricular passa a ofertar duas PPP, aos termos 1 e 2, com encontros quinzenais, em um dia da semana exclusivo para elas, prevendo que, nas semanas alternadas, os estudantes deverão ir a campo, para desenvolver seus estudos e vivências imersivas, em espaços educacionais formais e não formais.

Como já dito, três disciplinas - "Educação Especial”, "Teorias Pedagógicas", "Relações Étnico-raciais" - até então oferecidas como eletivas, passam a integrar a matriz curricular, com status de disciplinas obrigatórias. Para tanto, foi necessário rever a matriz curricular, aglutinando disciplinas correlatas. Nessa perspectiva, os conteúdos das disciplinas "Estudos sociológicos da escola" e "Perspectivas sociológicas sobre a educação" passam a ser trabalhados na disciplina "Sociologia e Educação: função da escola no Brasil”. E os conteúdos das disciplinas "Políticas públicas da educação brasileira" e "Políticas e organização da Educação Básica" passam a integrar a disciplina "Política Educacional no Brasil". Do mesmo modo, foi necessário alterar o status da disciplina "Educação e Psicanálise”, de obrigatória para eletiva.

Para que essa nova matriz curricular pudesse entrar em vigor, o colegiado do curso de Pedagogia (docentes e representação discente) reuniu-se diversas vezes, ponderando os desafios a serem enfrentados, bem como os pontos positivos e negativos de cada uma das aludidas modificações. Paralelamente, a equipe gestora conclamou todos os estudantes do Curso para uma reunião, para ouvi-los a respeito da almejada modificação curricular.

Após a aprovação interna ao Curso, por professores e estudantes, a atual matriz curricular tramitou institucionalmente em 2019, passando a vigorar a partir de março de 2020.

Apesar dos avanços até então empreendidos restam ao Curso inúmeros desafios, para se consolidar como um curso inovador, em que pese as citadas situações problemáticas: em nível macroestrutural (o desafio de organizar um curso a partir de orientações legais que deixam várias arestas abertas e a preocupação com a descontinuidade das ações afirmativas) e no que diz respeito aos determinantes circunstanciais do campus Guarulhos que abriga a EFLCH (cuja 
dificuldade de transporte público acaba por impactar negativamente a permanência dos estudantes).

\section{CONSIDERAÇÕES FINAIS}

O presente artigo procurou incidir luzes sobre os desafios e os avanços do curso de Pedagogia da Unifesp: um curso que, desde a sua gênese, se pretendeu inovador.

Os desafios a enfrentar foram delineados, observando-se o contexto de implantação do Curso e os fatores condicionantes de sua proposta: as Diretrizes Curriculares Nacionais para o Curso de Pedagogia, licenciatura (DCNP, 2006) e as Diretrizes da política nacional do REUNI (2007) - Reestruturação e Expansão das Universidades Federais.

Em relação às ações empreendidas no enfrentamento dos desafios que se interpõem ao Curso, os possíveis diferenciais do projeto pedagógico foram analisados, tendo por base o projeto acadêmico do campus Guarulhos onde se insere o curso de Pedagogia, bem como os eixos norteadores da sua matriz curricular, desde a sua primeira versão. Com base na literatura específica da área e em pesquisadores de renome, no campo do Currículo, tais como Goodson (1995) e Young (2014), a análise ora desenvolvida deflagra tensões oriundas das demandas sociais e dos constrangimentos legais.

É oportuno salientar que as políticas educacionais até então vigentes têm oferecido condições favoráveis para que as universidades públicas consigam auferir às suas licenciaturas um ethos acadêmico, cujas vivências formativas extrapolem em muito o âmbito da sala de aula.

Nessa perspectiva, a possibilidade de os estudantes de Pedagogia da Unifesp passarem por vivências formativas, por meio de programas como o PIBIC (Programa Institucional de Bolsa de Iniciação Científica), o PIBID (Programa Institucional de Iniciação à Docência), a monitoria, o PRP (Programa de Residência Pedagógica), as PPP (Práticas Pedagógicas e Pesquisa), entre outros, configura-se como um diferencial na formação do licenciando do Curso. Entretanto, esse caráter inovador do Curso depende, em grande medida, da manutenção de políticas educacionais que garantam condições favoráveis ao acesso e à permanência dos estudantes.

Por essa razão, mais do que nunca é necessário lutar pela manutenção de políticas educacionais voltadas à qualidade social (CONAE, 2018), no âmbito das universidades 
públicas. Tais políticas de modo algum se coadunam com o atual recrudescimento de políticas públicas voltadas à economia de custo, as quais negam o fato de que os gastos com Educação não se consubstanciam como custo, mas como investimento na construção do país.

\section{REFERÊNCIAS}

BRASIL, Ministério da Educação. Conselho Nacional de Educação. Resolução CNE/CP n. 1, de 15 de maio de 2006. Institui Diretrizes Curriculares Nacionais para o Curso de Graduação em Pedagogia, licenciatura. Disponível em: http://portal.mec.gov.br/cne/arquivos/pdf/rcp01_06.pdf Acesso em: 02 ago. 2020.

BRASIL, Ministério da Educação. Diretrizes Gerais. Reestruturação e Expansão da universidades Federais. REUNI, 2007. Disponível em:

http://portal.mec.gov.br/sesu/arquivos/pdf/diretrizesreuni.pdf Acesso em: 02 agosto. 2020.

BRANDT, Andressa Graziele; HOBOLD, Márcia de Souza. Mudanças e Continuidades dos Marcos Legais do Curso de Pedagogia no Brasil. Revista Internacional de Educação Superior. Campinas, SP v.5, n.1, 2019, p. 1-29. Disponível em: https://periodicos.sbu.unicamp.br/ojs/index.php/riesup/article/view/8652576 Acesso em: 02 ago. 2020.

\section{CONFERÊNCIA NACIONAL DE EDUCAÇÃO (CONAE). Documento Referência.} Brasília, DF: MEC, 2018. Disponível em:

http://conae.mec.gov.br/images/pdf/doc_referencia_conae_2018.pdf Acesso em: 02 ago. 2020.

EVANGELISTA, Olinda; TRINCHES, Jocemara. Docência, gestão e pesquisa nas Diretrizes Curriculares Nacionais para o Curso de Pedagogia. Revista Internacional de Formação de Professores (RIFP), Itapetininga, v. 2, n.4, 2017, p. 166-188. Disponível em: https://periodicos.itp.ifsp.edu.br/index.php/RIFP/article/view/1011 Acesso em: 02 ago. 2020.

FARIA, Juliana Batista; DINIZ-PEREIRA, Júlio Emílio. Residência pedagógica: afinal, o que é isso?. Revista de Educação Pública, v. 28, n. 68, 2019, p. 333-356, maio/ago., 2019. Disponível em:

http://periodicoscientificos.ufmt.br/ojs/index.php/educacaopublica/article/view/8393 Acesso em: 02 ago. 2020.

GOODSON, Ivor. Currículo: teoria e história. Petrópolis: Vozes, 1995.

GIGLIO, Celia Maria Benedicto; LUGLI, Rosario Silvana Genta. Diálogos pertinentes na formação inicial e continuada de professores e gestores escolares. A concepção do Programa de Residência Pedagógica na UNIFESP. Cadernos de Educação, n. 46, 2013, p. 62-82, set./dez., 2013. Disponível em:

https://periodicos.ufpel.edu.br/ojs2/index.php/caduc/article/view/4173 Acesso em: 02 ago. 2020. 
MARTINS, Edna. Família e escola no contexto de um programa de residência pedagógica: Um estudo a partir do enfoque histórico-cultural. Educação, Sociedade \& Culturas, São Paulo, n. 37, 2012, p. 89-107. Disponível em:

https://www.fpce.up.pt/ciie/sites/default/files/ESC37_E_Martins.pdf Acesso em: 02 ago. 2020.

MARTINS, Edna; CARVALHO, Maria de Fátima; CÂNDIDO, Renata Marcilio. Residência pedagógica em Educação Infantil: uma experiência em formação de professores. Educação (UFSM), v. 44, 2019, p. 30-1-22. Disponível em:

https://periodicos.ufsm.br/reveducacao/article/view/35694 Acesso em: 02 ago. 2020.

MICHELETTI, Elisângela Lisboa; GALIAN, Cláudia Valentina A. O Curso de Pedagogia: permanências e novas tensões. Revista Diálogo Educacional, vol. 17, núm. 55, outubrodezembro, 2017, p. 1688-1708. Disponível em:

https://periodicos.pucpr.br/index.php/dialogoeducacional/article/view/22676 Acesso em: 02 ago. 2020.

MORETTI, Vanessa Dias; MARTINS, Edna. Atividade de ensino, Mediação e Aprendizagem da docência na Residência Pedagógica: uma análise a partir da Teoria Histórico-Cultural.

Revista Contrapontos, v. 15, n. 3, 2015, p. 394-411, set./dez., 2015. Disponível em: https://siaiap32.univali.br/seer/index.php/rc/article/view/5993 Acesso em: 02 ago. 2020.

PIMENTA, Selma Garrido et al. Os cursos de licenciatura em pedagogia: fragilidades na formação inicial do professor polivalente. Educação e Pesquisa, São Paulo, v. 43, n. 1, p. 1530, mar. 2017. Disponível: http://www.scielo.br/pdf/ep/v43n1/1517-9702-ep-43-1-0015.pdf. Acesso em: 02 ago. 2020.

RODRIGUES, Marli de Fátima; KUENZER, Acácia Zeneida. As diretrizes curriculares para o Curso de pedagogia: uma expressão da epistemologia da prática. Olhar de professor, Ponta Grossa, v. 10, n. 1, 2007, p. 35-62. Disponível em:

https://www.revistas2.uepg.br/index.php/olhardeprofessor/article/view/1474 Acesso em: 02 ago. 2020.

SÃO PAULO. Universidade Federal de São Paulo. Análise do perfil socioeconômico e cultural de ingressantes na Universidade Federal de São Paulo. PRAE - PROGRAD CEPEG/ Unifesp, 2016.

SÃO PAULO. Universidade Federal de São Paulo. Pró-reitora de Graduação. Departamento de Educação. Projeto Pedagógico do Curso de Pedagogia - PPC, 2019.

SCHEIBE, Leda. Diretrizes Curriculares para o Curso de Pedagogia: trajetória longa e inconclusa. Cadernos de Pesquisa, v. 37, n. 130, 2007, p. 43-62 jan./abr., 2007. Disponível em: https://www.scielo.br/pdf/cp/v37n130/04.pdf Acesso em: 02 ago. 2020. 
YOUNG, Michael. Teoria do currículo: o que é e por que é importante. Cadernos de

Pesquisa, v. 44, n.151, p.190-202 jan./mar. 2014. Disponível em:

http://publicacoes.fcc.org.br/ojs/index.php/cp/article/view/2707 Acesso em: 02 ago. 2020.

Recebido em: 07/05/2020

Aprovado em: 08/08/2020 